\title{
Epidemiology of skin and soft tissue pathogens circulating in Liguria in 20 I I
}

\author{
Erika Coppo', Ramona Barbieri', Andrea Dusi ${ }^{2}$, Marco Mori', David Usiglio³, Luigi Carlo \\ Bottaro4, Paolo Piazzai ${ }^{4}$, Luisa Santoriello ${ }^{5}$, Agostina Ronca $^{5}$, Anna Marchese', Eugenio A. \\ Debbia'
}

I Sezione di Microbiologia DISC, Università degli Studi di Genova

2 ASL I Imperiese, Imperia

3 Ente Ospedaliero Galliera, Genova

4 Ospedale Evangelico Internazionale, sede di Voltri, Genova

5 Ospedale Santa Corona, Pietra Ligure(SV)

Key words: Skin infections, MRSA, Antimicrobial agents

\section{SUMMARY}

This study was conduced during March-May 20I I with the collaboration of 4 clinical microbiology laboratories evenly distibuited across the Ligurian area to identify the most frequent pahogens isolates from skin and soft tissue infections and to evaluate their antibiotic susceptibility patterns. Overall, 2 I 3 consecutive, non duplicate strains were collected and sent to the coordinating laboratory. The most rappresented pathogens were: $S$. aureus (35.7\%), P. aeruginosa (I4\%), E. coli (I2.7\%), Staphylococcus coaugulase negative (6.6\%) and Enterococcus spp. (4.7\%). The data indicate an increase of Gram negative compared to previous years, S. aureus remains the most common pathogen. The methicillin resistance in S. aureus was $43.4 \%$ and no one Enterococcus spp. resistant to vancomicin was found.

\section{INTRODUCTION}

Skin ans soft tissue infections are ubiquitous and the most common of infections and reflect infiammatory microbial invasion of epidermidis, dermis and subcutaneus tissues.

The skin is colonized with an indigeneous microbial flora, which typiccaly consist of variety of species of staphylococci, corynebacteria, propinobacteria and yeast, in number that may vary from a few hundred to many thousands per square centimetre in the moister areas as the groin and axillae (7).

Empirical antibiotic regimens for complicated skin-structure infections should always include coverage for aerobic Gram-positive cocci, specifically staphylococci and streptococci, and often for anaerobes, including the Bacteroides fragilis group $(1,5,8)$. Methicillin-resistant $S$. aureus and Gramnegative bacilli are found in some mixed infections, especially those that occur in the hospital (3). Gram-negative organisms and methicillin-resistant staphylococci assume greater importance in superinfections after multiple courses of antibiotics, and in infections associated with profound neutropenia or injection drug use $(4,6,9)$.

This survey was planned to identify the most frequent species isolate from skin and soft tissue infections and to evaluate suscetibility patterns among bacteria collected from clinical sample in Liguria.

\section{MATERIAL AND METHODS}

\section{Bacterial isolates}

This study was conduced during March 2011-May 2011 with the collaboration of 4 clinical microbiology laboratorys in the ligurian area. The entrolled laboratories were: ASL Imperiese, Imperia; Ente ospedaliero Galliera Hospital, Genoa; International Evangelical Hospital (Voltri division), Genoa; Santa Corona Hospital, Pietra Ligure, Savona.

Overall, 213 consecutive skin and soft tissue isolates were collected and sent to the co-ordinating laboratory(Microbiology Section, DISC, University of Genoa). Strains isolates from in and out-patients were studied, with the exception of duplicate strains from the same patient. Participating laboratories also provided susceptibility data obtained by their routine method.

\section{Antimicrobial susceptibility testing}

Minimum inibitory concentrations were determined by the broth microdiluition method suggested by Clinical Laboratory standard Institute (CLSI) (2). The results were reported as susceptible resistant in accordance to CLSI raccomandation and compared with those obtained by the original laboratory.

\section{Corresponding author: Erika Coppo}

Sezione di Microbiologia, C.A. Romanzi; Facoltà di Medicina e Chirurgia-DISC

Largo Rosanna Benzi, I0 - I6I32 Genova - Tel.: 0103538998 - Fax: 010353765 I

E-mail: coppo@unige.it 
Escherichia coli ATCC 25922, Pseudomonas aeruginosa ATCC 27853 and Staphylococcus aureus ATCC 29213 were used as quality control strains.

\section{RESULTS}

Table 1 summaries the complete list and the distribution of the pathogens collected in this study.

A total of 213 skin and soft tissue isolates were found, including 111 and 102 isolated from helthcare setting or nosocomial and community acquired infections, respectively.

The most represented pathogens were: $S$. aureus $(76,35.7 \%), P$. aeruginosa $(30,14 \%)$, E. coli $(27$, $12.7 \%)$, Staphylococcus coagulase negative (CoNS) $(14,6.6 \%)$. Nosocomial samples were collected mainly from patients hospitalized in general medicine wards $(31,27.9 \%)$, surgery $(17$, $15.3 \%$ ), Nefrology and health care settings (HCS) (11, 9.9\%), Infectious disease, orthopedic wards and cardiology $(7,6.3 \%), \operatorname{ICU}(5,4.5 \%)$ and other wards $(15,13.5 \%)$.

Table I. Distribuition of the strains collected in this survery according to the origin.

\begin{tabular}{|c|c|c|c|c|}
\hline \multicolumn{5}{|c|}{ NUMBER AND ORIGIN } \\
\hline STRAINS & NOS-HC & COM & TOT & $\%$ \\
\hline S. aureus & 39 & 37 & 76 & 35.7 \\
\hline CoNS & 7 & 7 & 14 & 6.6 \\
\hline P. aeruginosa & 17 & 13 & 30 & 14 \\
\hline E. coli & 17 & 10 & 27 & 12.7 \\
\hline $\begin{array}{l}\text { Other Enterobacteriaceae } \\
\text { (P. mirabilis, I5; C. koseri, I; E. cloacae, } \\
3 ; K . \text { oxytoca, } 2 ; K \text {. pneumoniae, II;M. } \\
\text { morganii, 3;P. rettgeri, I;P. stuartii, I;P. } \\
\text { vulgaris, I; S. marcescens, } 5\end{array}$ & 20 & 23 & 43 & 20.2 \\
\hline $\begin{array}{l}\text { Other Non Enterobacteriaceae } \\
\text { (A. baumanni, 3; A. xylosoxidans, I; B. } \\
\text { cepacia, I; S. malthophilia, 2) }\end{array}$ & 3 & 4 & 7 & 3.3 \\
\hline Enterococcus spp. & 4 & 6 & 10 & 4.7 \\
\hline Streptococcus spp. & 4 & 2 & 6 & 2.8 \\
\hline Total & 111 & 102 & 213 & \\
\hline$\%$ & 52.1 & 47.9 & & \\
\hline
\end{tabular}

Bacterial isolates were obtained from ulcer (87, $40.8 \%)$, skin swab $(65,30.5 \%)$ and wound swab $(61,28.6 \%)$.

The antibiotics susceptibility patterns of the strains collected is displayed in Table 2.

$56.6 \%$ of $S$. aureus was susceptible to oxacillin. Vancomycin, Linezolid Trimethoprim-sulfamethxazole and Tigecicline were the most active molecule against $S$. aureus MSSA (100\% of susceptible strains), followed by Tetracicline $(97.7 \%)$, Rifampicine (95.3\%), Ciprofloxacin $(88.4 \%)$ and Gentamicin $(69.9 \%), 43.4 \%$ of $S$. aureus was resistant to oxacillin (MRSA). Vancomycin, Linezolid and Tigecicline were the most active molecule against $S$. aureus MRSA (100\%), followed by Rifampicine, Gentamicin $(81.8 \%)$ and Tetracicline (78.8\%). The other molecules (Trimethoprim-sulfamethxazole and ciprofloxacin) showed rate of resistence higher than $60 \%$.

Tigecicline was the most effective molecule against $P$. aeruginosa followed by Ceftazidime (70\%), Tobramicine (66.7\%) and Imipenem (60\%).

The other molecule (Ciprofloxacin and Gentamicin) showed rate of resistance higher than $50 \%$.

Tigecicline and Imipenem were the most effective molecule against E. coli $(100 \%)$, followed by Gentamicin (88.9\%), Ceftazidime (74.1\%), Amoxicillin-Clavulanate and Ciprofloxacin (74.1\%) and Trimethoprim-sulfamethxazole $(63 \%)$.

All Enterococcus spp. was susceptible to Vancomicin.

\section{CONCLUSION}

This report described the epidemiology of skin and soft tissue isolates in Liguria and their antibiotics susceptibility patterns, evaluating saples from over 213 patients recluited by 4 hospitals.

Table 2. Percentage of susceptibility to major classes of antibiotics.

\begin{tabular}{|c|c|c|c|c|c|c|c|c|c|c|c|c|c|c|c|}
\hline & OXA & VAN & LZD & SXT & RIF & TC & GM & ERI & AMP & AMC & $\mathrm{CIP}$ & CAZ & IMI & TOB & TIG \\
\hline $\begin{array}{l}\text { S. aureus OXA S } \\
(56,6 \%)\end{array}$ & & 100 & 100 & 100 & 95.3 & 97.7 & 69.8 & & & & 88.4 & & & & 100 \\
\hline $\begin{array}{l}\text { S. aureus OXA R } \\
(43,4 \%)\end{array}$ & & 100 & 100 & 37 & 81.8 & 78.8 & 81.8 & & & & 12.1 & & & & 100 \\
\hline CoNs & 35.7 & 100 & 100 & 71.4 & 85.7 & 50 & 50 & & & & 64.3 & & & & 100 \\
\hline P. aeruginosa & & & & 0 & & & 46.7 & & & & 43.3 & 70 & 60 & 66.7 & 86.7 \\
\hline E. coli & & & & 63 & & & 88.9 & & 22.2 & 70.4 & 70.4 & 74.1 & 100 & & 100 \\
\hline $\begin{array}{l}\text { Other } \\
\text { Enterobacteriaceae }\end{array}$ & & & & 60.5 & & & 74.4 & & & 65.1 & 62.8 & 83.7 & 81.4 & & \\
\hline Enterococcus spp. & & 100 & & 0 & & 75 & 50 & 10 & 80 & & 80 & & & & 100 \\
\hline
\end{tabular}


The need for local, national or international survellance to evaluate the rate of bacterial resistance to antibiotics, is generally suggested in order to chose the best drug in empiric therapy, and to gain information about the emerging pathogens and their identification, as well as evolution toward resistance to the more frequently used antimicrobials.

S. aureus was the most frequent pathogens isolated from Healthcare setting and from community acquired infections, wich accounted for $35.7 \%$ of all isolates collected. $43.4 \%$ of $S$. aureus was MRSA, 47\% (16/34) Helthcare, 32.4\% (12/37) community and $100 \%(5 / 5)$ RSA. The new agents for the treatment of methicillin-resistant $S$. aureus infections (Linezolid and Tigecicline) are active against all MRSA.

$P$. aeruginosa has been isolated mainly from nosocomial patients $(56.7 \%)$ and in ulcer sample $(50 \%)$. Tigecicline is the most effective molecule against this pathogen and all $P$. aeruginosa are resistant to Trimethoprim-sulfamethxazole.

As regards the non-enterobacteriaceae strains there were no high percentages of resistance.

All Enterococcus spp. were susceptible to vancomicin.

\section{REFERENCES}

1. Bowler PG, Duerden BI, Armstrong DG. Wound microbiology and associated approaches to wound management. Clinical Microbiology Reviews 2001; 14: 244-69.

2. Clinical and Laboratory Standards Institute (CLSI). Performance Standards for Antimicrobial Susceptibility Testing: Twenty-second Informational Supplement. 2011; M100-S21. CLSI, Wayne, PA, USA.

3. Doern GV, Jones RN, Pfaller MA, et al. Bacterial pathogens isolated from patients with skin and soft tissue infections: frequency of occurrence and antimicrobial susceptibility patterns from the SENTRY Antimicrobial Surveillance Program (United States and Canada, 1997). SENTRY Study Group (North America). Diagnostic Microbiology and Infectious Disease 1999; 34: 65-72.

4. Fustes-Morales A, Gutierrez-Castrellon P, DuranMckinster C, et al. Necrotizing fasciitis: report of 39 pediatric cases. Archives of Dermatology 2002; 138: 893-9.

5. Gerding DN. Foot infections in diabetic patients: the role of anaerobes. Clinical Infectious Diseases 1995; 20 (2): S283-8.

6. Manfredi R, Calza L, Chiodo F. Epidemiology and microbiology of cellulitis and bacterial soft tissue infection during HIV disease: a 10-year survey. Journal of Cutaneous Pathology 2002; 29: 168-72.

7. Mims C, Playfair J, Roitt I, et al. Medical microbiology. Mosby Int Ltd, London. ISBN 072342781 X.

8. Reyzelman AM, Lipsky BA, Hadi SA, et al. The increased prevalence of severe necrotizing infections caused by non-group A streptococci. Journal of the American Podiatric Medical Association 1999; 89: 454-7.

9. Summanen PH, Talan DA, Strong C, et al. Bacteriology of skin and soft-tissue infections: comparison of infections in intravenous drug users and individuals with no history of intravenous druguse. Clinical Infectious Diseases 1995; 20 (2): S279-82. 